\title{
Child self-report and child-parent agreement regarding health- related quality of life under COVID-19 lockdown in the French Grand Est area
}

Stephanie Bourion-Bedes ( $\nabla$ steph_bedes@yahoo.fr)

Centre de pédopsychiatrie: Centre de pedopsychiatrie

\section{Hélène Rousseau}

CHU Nancy: Centre hospitalier regional universitaire de Nancy

\section{Martine Batt}

Université de Lorraine: Universite de Lorraine

Pascale Tarquinio

Universite de Lorraine

Romain Lebreuilly

Université de Lorraine: Universite de Lorraine

\section{Christine Sorsana}

Université de Lorraine: Universite de Lorraine

\section{Karine Legrand}

Nancy Regional University Hospital Center: Centre hospitalier regional universitaire de Nancy

Cyril Tarquinio

Université de Lorraine Site Nancy: Universite de Lorraine

\section{Cedric Baumann}

Université de Lorraine Site Nancy: Universite de Lorraine

Research article

Keywords: COVID-19, health-related quality of life, KIDSCREEN-27, children

Posted Date: April 12th, 2021

DOI: https://doi.org/10.21203/rs.3.rs-392956/v1

License: () (7) This work is licensed under a Creative Commons Attribution 4.0 International License. Read Full License 


\section{Abstract}

Purpose: Billions of children worldwide were sent under lockdown due to the coronavirus disease. This study aimed to investigate child-reported and parent-rated health-related quality of life among 8- to 18-year-olds and the agreement between the children's assessments and those of their parents during lockdown.

Methods: A cross-sectional study was conducted among French children living in the Grand Est area. An online survey was used to collect data on the children's sociodemographics, living environments, education and HRQoL. The latter was assessed with KIDSCREEN-27, which consists of five domains. Sex and age differences in parent ratings and child-reported data were analyzed using Kruskal-Wallis tests. Child-parent agreement was analyzed using the intraclass correlation coefficient (ICC).

Results: In total, 471 child-parent pairs from 341 households were included. Compared to European norms, children scored lower on all dimensions during the first lockdown: physical well-being (45.9/49.94 EU), psychological well-being (48.8/49.77 EU), parent relations and autonomy (47.7/49.99 EU), social support and peers (36.4/49.94) and school (48.2/50). Significant child-reported sex and age differences were identified for both psychological and physical well-being dimensions. Moderate to good agreement existed between children's and parents' ratings on all KIDSCREEN dimensions (ICC ranged from 0.60 to 0.76 ).

Conclusion: The study suggests the need to focus on children's social support and peers during epidemics and to consider the children's self-reported HRQoL. Additional research should be conducted to identify ways of minimizing the gap between mental health needs and the services available and to help more children maintain their physical and mental health during the current crisis.

\section{Introduction}

Coronavirus disease 2019 (COVID-19), which is caused by infection with severe acute respiratory syndrome coronavirus 2 (SARSCoV-2), emerged in Wuhan, China [1,2] and has rapidly spread worldwide, becoming a pandemic that is affecting every continent [3]. The increasing number of confirmed cases and deaths has led to panic and stress in the general public [4]. To contain the spread of COVID-19, the French government decided to implement stringent containment measures nationwide on March 16, 2020. The pandemic has had a tremendous impact on human health and has necessitated lifestyle changes to enforce social distancing and isolation at home; these changes have had social and economic consequences [5]. Although the incidence of COVID-19 among young children and adolescents is low, the stress and emotional disturbances caused by the pandemic and the necessary containment measures mean that they are highly vulnerable to adverse mental health effects [6]. Child and adolescent populations are indeed particularly vulnerable during a pandemic, as they are suddenly faced with societal and economic changes that are necessary to control the disease and protect the population [7]. Social support and peer interactions are essential for the normal psychological development and wellbeing of children and adolescents. School closures during the lockdown led to reductions in adolescents' and children's activities and peer contacts, decreased physical activity, increased screen time, irregular sleep patterns, and a less appropriate diet [8-9]. In addition, children and adolescents who do not attend school lack the usual monitoring by education professionals or other adults who, under normal conditions, would have noticed their distress. In addition, under conditions of home confinement, parents may be less available to their children and have a more punitive attitude towards them [7]. Some children have parents who are involved in working to combat COVID-19, while others have parents who now work from home or have recently lost their financial independence due to the loss of the job [10]. Furthermore, children and adolescents are exposed to a continuous flow of information that can lead to a lack of comprehension and psychological insecurity, compounded by the stress and anxiety the children can sense in the adults around them [11].

Health-related quality of life (HRQoL) is a patient's subjective perception of his/her satisfaction with his/her own health, and subjective perceptions are directly related to the psychological state of the individual [12]. Previous research among 8079 Chinese adolescents aged 12-18 reported high prevalences of depression symptoms (43.7\%), anxiety symptoms (37.4\%) and both (31.3\%) during the COVID-19 epidemic [13]. Among 2330 Chinese students in grades 2 through $6,22.6 \%$ and $18.9 \%$ reported depression and anxiety symptoms, respectively [14]. A recent study also highlighted that high school students had higher prevalences of anxiety and stress than junior high school students [15]. Moreover, it has been previously found that compared to adults, children and adolescents may experience more severe long-term adverse consequences of this pandemic [16]. Therefore, it

Page 2/13 
is believed that the COVID-19 pandemic is affecting the HRQoL of children and adolescents [17], and it is well known that mental health is an essential factor in quality of life [13]. Although the data available on the psychological effects of the pandemic in youth have accumulated during the pandemic [13-14, 18], information about the immediate consequences of the COVID-19 pandemic and lockdown on quality of life in children and adolescents remains scarce. The use of HRQoL questionnaires completed by children has increased, as the information provided about emotional or clinical problems by the children themselves is preferable, given the possibility of parent-child discrepancies in reporting [19]. Thus, this study aimed to a) investigate the HRQoL in children and adolescents from the Grand Est region, which is the French region that was the third most severely affected by the disease during the first wave, and b) analyze child-parent agreement during the pandemic and the first lockdown.

\section{Methods}

\section{Design and participants}

This study was a cross-sectional analysis of data from the observational Feelings and Psychological Impact of the COVID-19 Epidemic Among Children, Adolescents and their Parents in the Grand Est Area (PIMS2-CoV19) study. An online survey was conducted from May 26th to July 6th, 2020, on a platform that was accessible with an internet connection. From a complete list of middle and high schools in the Grand Est area, schools were randomly selected using proportionate stratification for the baseline ascertainment and recruitment. In each selected school, the survey was disseminated through school institutional mailing lists. Children and parents were instructed to access a link containing instructions and information about the study. The survey included an informed consent form; questions about demographics and living conditions during the lockdown; the Generalized Anxiety Disorder-7 (GAD-7), which was to be completed by the parents; and both generic versions of the KIDSCREEN27 questionnaire, with a version to be completed by the children/adolescents and another version to be independently completed by the parents [20]. All data were obtained at the time of the online survey. The study was conducted in full compliance with the national regulations and the principles of the Declaration of Helsinki. The anonymous nature of the web survey did not allow us to trace personal data in any way. The study protocol was approved by the Institutional Review Board (Comité National Informatique et Liberté-registration 2220408)

\section{Measures}

\section{Health-Related Quality of Life}

The KIDSCREEN-27 is the mid-length option among the KIDSCREEN instruments. It was derived using psychometric methods from the KIDSCREEN-52 to provide an instrument that might be useful in epidemiological and clinical studies [21-22]. The French version of the questionnaire has been confirmed to have good internal consistency, with Cronbach's alpha coefficients ranging from 0.8 to 0.84 , and good reliability, with values ranging from 0.61 to 0.74 [20]. It measures five dimensions: physical well-being (5 items), which explores the child's levels of physical activity, energy, and fitness, as well as the extent to which a child feels unwell and complains of poor health; psychological well-being (7 items), which examines the psychological well-being of the child, including their positive emotions and satisfaction with life as well as the absence of feelings such as loneliness and sadness; parent relations and autonomy (7 items), which explores their relationships with their parents, the atmosphere at home, and feelings of having enough age-appropriate freedom of choice as well as feeling satisfied with their own financial resources; social support and peers (4 items), which examines the quality of the interactions between the child and his/her peers as well as their perceived support; and the school environment (4 items), which explores the child's perceptions of his/her cognitive capacity, learning and concentration, and feelings about school. The items in both the parent and child/adolescent versions are answered on a five-point Likert-type scale assessing the frequency with which the child experiences the given feeling as never (1), seldom (2), sometimes (3), often (4), and always (5) or the intensity as not at all (1), slightly (2), moderately (3), very (4), and extremely (5), with a 1-week recall period. Scores are coded from 1 to 5 . Negatively formulated items are recoded, and higher summed scores indicate better HRQoL. Rasch scores are computed for each dimension and transformed into values with a mean of 50 and standard deviation of 10. Normative reference values are available for 11 European countries [23]. KIDSCREEN-27 takes approximately 10 minutes to complete.

\section{Sociodemographic data and other characteristics}


The collected demographic data were the children's/adolescents' age, sex, education level and learning conditions. Participants were stratified by age upon questionnaire completion as children (8-11 years old) or adolescents (12-18 years old) and by sex.

\section{Statistical analyses}

Data are represented as numbers and percentages for categorical variables and as the means \pm standard deviations (SDs) for continuous variables. Kruskal-Wallis tests were used to compare variables between groups. The results were significant when the $p$ value was $<0.05$. Agreement between child and parent HRQoL ratings was assessed using ICCs. ICC values $<0.4$ were considered poor to fair, those between 0.41 and 0.6 were moderate, and those $>0.6$ were substantial to nearly perfect [24]. To complete the analysis, the Bland and Altman approach was used as a complementary method to visually represent the agreement between raters. The resulting graph is a scatter plot, in which the $Y$ axis shows the difference between the two paired measurements (e.g., parent ratings-child ratings) and the $X$ axis represents the average of those ratings. The statistical limits of agreement between KIDSCREEN raters were estimated by calculating the mean difference and the standard deviation of the difference. More specifically, 95\% of differences will lie between the mean-1.96 SD and the mean+1.96 DS if the differences are normally distributed. This approach allowed us to visually examine the extent of the disagreement. Formal agreement was only possible when the two scores (parent ratings-child ratings) were perfectly correlated (scatter is zero) and the bias (elevation and spread) between them was zero [25]. Statistical analysis was performed using SAS 9.4 (SAS Inst., Cary, NC, USA).

\section{Results}

\section{Sociodemographic, learning and living characteristics}

The analysis included 471 child-parent pairs from 341 distinct households. As shown in Table 1, more than half of the children were female $(53.5 \%)$. The average age was 12.9 years $(S D=3.0), 40 \%$ of the children were younger than 12 years, and $39.7 \%$ were identified as primary school graduates. One-quarter of the sample (25.7\%) reported spending less than 2 hours/day on homework during the lockdown. Of the 471 participants, $29.1 \%$ reported conflicts with family members in their house, and $13.2 \%$ found it difficult to isolate themselves in the dwelling. 
Table 1

Sociodemographic, living environment and education characteristics of the study sample during the lockdown $(\mathrm{N}=471)$

\begin{tabular}{|c|c|c|}
\hline & \multicolumn{2}{|c|}{ Full sample } \\
\hline & $\mathrm{N}$ & $\% /$ Mean (SD) \\
\hline \multicolumn{3}{|c|}{ Sociodemographic and education characteristics } \\
\hline \multicolumn{3}{|l|}{ ( $N=471$ children $)$} \\
\hline Age & 471 & $12.9(3.0)$ \\
\hline \multicolumn{3}{|l|}{ Sex } \\
\hline Male & 219 & 46.5 \\
\hline Female & 252 & 53.5 \\
\hline \multicolumn{3}{|l|}{ Education level } \\
\hline Primary school & 187 & 39.7 \\
\hline Middle school & 171 & 36.3 \\
\hline High school & 113 & 24.0 \\
\hline \multicolumn{3}{|c|}{ Time spent on schoolwork at home (missing = 4) } \\
\hline$\geq 4$ hours a day & 137 & 29.4 \\
\hline $2-4$ hours a day & 209 & 44.8 \\
\hline $1-2$ hours a day & 97 & 20.8 \\
\hline$<1$ hour a day & 23 & 4.9 \\
\hline \multicolumn{3}{|c|}{ Difficulty isolating at home } \\
\hline Yes & 62 & 13.2 \\
\hline No & 409 & 86.8 \\
\hline \multicolumn{3}{|c|}{ Tensions and conflicts at home } \\
\hline Yes & 137 & 29.1 \\
\hline No & 334 & 70.9 \\
\hline \multicolumn{3}{|c|}{ Living environment characteristics ( $N=341$ households) } \\
\hline \multicolumn{3}{|c|}{ Living arrangements (missing = 2) } \\
\hline Both parents & 230 & 67.8 \\
\hline Single parent & 19 & 5.6 \\
\hline Separated parents & 90 & 26.6 \\
\hline \multicolumn{3}{|c|}{ Home location (missing = 2) } \\
\hline Urban area & 131 & 38.6 \\
\hline Rural area & 208 & 61.4 \\
\hline \multicolumn{3}{|c|}{ Access to a private outside space } \\
\hline No access & 22 & 6.5 \\
\hline Abbreviation: SD, s & & \\
\hline
\end{tabular}




\begin{tabular}{|lll|}
\hline & \multicolumn{2}{l|}{ Full sample } \\
\hline Private balcony, courtyard or terrace & 38 & 11.1 \\
\hline Private domestic garden & 270 & 79.2 \\
\hline Courtyard or garden for collective use & 11 & 3.2 \\
\hline Someone in the household infected with COVID-19 & & \\
\hline No & 299 & 87.7 \\
\hline Confirmed and hospitalized cases & 3 & 0.9 \\
\hline Confirmed but nonhospitalized cases & 7 & 2.1 \\
\hline Suspected cases & 32 & 9.4 \\
\hline Relative or acquaintance infected with COVID-19 & & \\
\hline No & 211 & 61.9 \\
\hline Confirmed and hospitalized cases & 28 & 8.2 \\
\hline Confirmed but nonhospitalized cases & 70 & 20.5 \\
\hline Suspected cases & 32 & 9.4 \\
\hline Abbreviation: SD, standard deviation & & \\
\hline
\end{tabular}

In the 341 households, $85 \%$ of the respondents were mothers, more than one-third lived (38.6\%) in urban areas, and $6.5 \%$ reported having no access to outdoor areas. Both parents were living in the same home in two-thirds $(67.8 \%)$ of the households. More than one-third of the households (38.1\%) had a relative or acquaintance who had COVID-19, and $12.3 \%$ had someone in their house who had COVID-19.

\section{Kids' HRQoL scores and parents' ratings during the pandemic and the lockdown}

The mean HRQoL scores of the children and the parents' ratings are shown in Table 2. With regard to the KIDSCREEN-27 dimensions, the children's highest average scores were $48.8 \pm 10$ for "psychological well-being" and $48.2 \pm 10.2$ for "school environment", while their lowest average scores were $36.4 \pm 14.7$ for "social support and peers" and $45.9 \pm 10.3$ for "physical wellbeing". Significant differences were found between age groups for all dimensions. The younger group (8-11 years) scored lower on the social support \& peers $(p<0.0001)$ and parent relations and autonomy $(p=0.04)$ dimensions than the older group $(12-18$ years). Regarding psychological well-being, adolescents scored lower than children in the 8-11 year group $(p<0.0001)$. Regarding their physical and psychological well-being, girls scored lower than boys $(p=0.005$ and $p=0.0008$, respectively). No significant sex differences were found in the dimensions parent relations and autonomy $(p=0.62)$, social support and peers ( $p=$ $0.07)$ and school environment $(p=0.37)$. All scores provided by the parents were lower than those provided by the children. 
Table 2

Children's scores and parents' ratings on KIDSCREEN-27 by the children's age and sex group

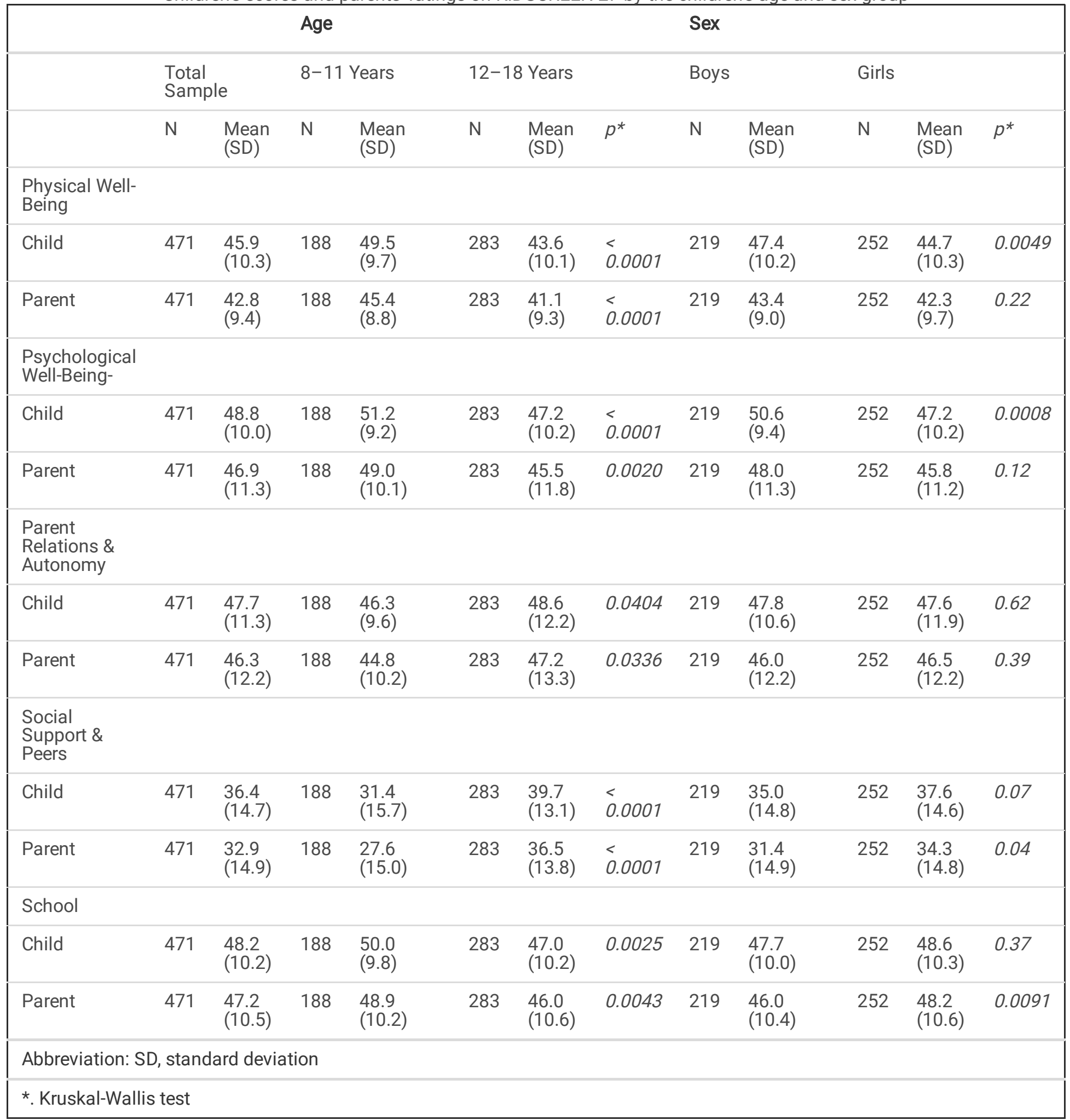

\section{Child-parent agreement on the KIDSCREEN-27}

Table 3 shows the ICCs between the child and parent scores on the KIDSCREEN-27. The ICCs between child and parent scores ranged from moderate ( 0.60 for psychological well-being) to good ( 0.76 for social support and peers). The Bland and Altman plots (Fig. 1) showed that the mean differences in pairwise agreement on items in the 5 dimensions of the KIDSCREEN-27 scores differed from zero. The $95 \%$ limits of agreement between parents and children were: -3.09 for physical well-being (95\% $\mathrm{Cl}=-3.76 ;-2.41$, Fig. 1A1); -1.93 for psychological well-being (95\% $\mathrm{Cl}=-2.79 ;-1.08$, Fig. 1A2); -1.44 for parent relations and autonomy (95\% Cl=-2.33;-0.54, Fig. 1A3); -3.49 for social support and peers (95\% Cl=-4.36;-2.62, Fig. 1A4); and - 1.02 for school environment 
(95\% $\mathrm{Cl}=-1.79 ;-0.27$, Fig. 1A5). Visual inspection of the Bland-Altman plot for the psychological dimension showed that when the average well-being score reported by the children was lower (x-axis), the parents' assessment was fairly accurate, as shown by the relatively substantial proportion of cases along the zero-bias line. However, as the mean well-being score reported by the children increased, the parents' scores increasingly differed, as indicated by the higher proportion of cases above and below the zero-bias line (Fig. 1).

Table 3

Child-parent agreement on the KIDSCREEN-27 questionnaire by sex and age group

\begin{tabular}{|c|c|c|c|c|c|c|c|c|c|c|}
\hline & \multicolumn{2}{|c|}{ Total Sample } & \multicolumn{4}{|l|}{ Age } & \multicolumn{4}{|l|}{ Sex } \\
\hline & \multicolumn{2}{|c|}{$N=471$} & \multicolumn{2}{|c|}{$\begin{array}{l}8-11 \text { Years } \\
(N=188)\end{array}$} & \multicolumn{2}{|c|}{$\begin{array}{l}12-18 \text { Years } \\
(N=283)\end{array}$} & \multicolumn{2}{|c|}{$\begin{array}{l}\text { Boys } \\
(\mathrm{N}=219)\end{array}$} & \multicolumn{2}{|c|}{$\begin{array}{l}\text { Girls } \\
(N=252)\end{array}$} \\
\hline & ICC & $95 \% \mathrm{Cl}$ & ICC & $95 \% \mathrm{Cl}$ & ICC & $95 \% \mathrm{Cl}$ & ICC & $95 \% \mathrm{Cl}$ & ICC & $\begin{array}{l}95 \% \\
\mathrm{Cl}\end{array}$ \\
\hline $\begin{array}{l}\text { Physical Well- } \\
\text { Being }\end{array}$ & 0.68 & $\begin{array}{l}0.62- \\
0.72\end{array}$ & 0.59 & $\begin{array}{l}0.49- \\
0.67\end{array}$ & 0.69 & $\begin{array}{l}0.63- \\
0.75\end{array}$ & 0.61 & $\begin{array}{l}0.52- \\
0.69\end{array}$ & 0.72 & $\begin{array}{l}0.66- \\
0.77\end{array}$ \\
\hline $\begin{array}{l}\text { Psychological } \\
\text { Well-Being }\end{array}$ & 0.60 & $\begin{array}{l}0.54- \\
0.65\end{array}$ & 0.60 & $\begin{array}{l}0.50- \\
0.69\end{array}$ & 0.58 & $\begin{array}{l}0.49- \\
0.65\end{array}$ & 0.51 & $\begin{array}{l}0.41- \\
0.60\end{array}$ & 0.66 & $\begin{array}{l}0.58- \\
0.72\end{array}$ \\
\hline $\begin{array}{l}\text { Parent Relations \& } \\
\text { Autonomy }\end{array}$ & 0.64 & $\begin{array}{l}0.58- \\
0.69\end{array}$ & 0.62 & $\begin{array}{l}0.52- \\
0.70\end{array}$ & 0.64 & $\begin{array}{l}0.57- \\
0.71\end{array}$ & 0.64 & $\begin{array}{l}0.55- \\
0.71\end{array}$ & 0.64 & $\begin{array}{l}0.56- \\
0.71\end{array}$ \\
\hline $\begin{array}{l}\text { Social Support \& } \\
\text { Peers }\end{array}$ & 0.76 & $\begin{array}{l}0.72- \\
0.80\end{array}$ & 0.81 & $\begin{array}{l}0.76- \\
0.86\end{array}$ & 0.68 & $\begin{array}{l}0.62- \\
0.74\end{array}$ & 0.75 & $\begin{array}{l}0.69- \\
0.81\end{array}$ & 0.77 & $\begin{array}{l}0.71- \\
0.82\end{array}$ \\
\hline School & 0.67 & $\begin{array}{l}0.62- \\
0.72\end{array}$ & 0.61 & $\begin{array}{l}0.51- \\
0.69\end{array}$ & 0.70 & $\begin{array}{l}0.63- \\
0.75\end{array}$ & 0.65 & $\begin{array}{l}0.56- \\
0.72\end{array}$ & 0.69 & $\begin{array}{l}0.62- \\
0.75\end{array}$ \\
\hline
\end{tabular}

\section{Discussion}

The children and adolescents in the present study had lower HRQoL scores than the European sample in a previous reference study [21]. The difference can be interpreted as being clinically important [26]. These findings are in line with previous studies that showed that psychological distress increased in younger children after the school lockdown [27]. Children have had relatively sedentary lifestyles while confined to their homes after the closure of schools due to the need to enforce social isolation. Therefore, it is unsurprising that the children had markedly lower scores on the dimensions addressing social support through peer interactions and physical well-being. In agreement with a previous study, differences were identified in HRQoL based on sex and age. In line with the normative European data for children and adolescents, children aged 8-11 years scored higher than adolescents aged 12-18 years on nearly all KIDSCREEN-27 dimensions, especially physical well-being and psychological wellbeing. In contrast, children had lower scores than adolescents for the dimension of social support and peer interactions, indicating that the negative effects on this dimension particularly affected children. These results might be explained in several ways. Spending time with friends has been found to be essential for adolescents' quality of life, and adolescents may have kept in touch with a few important friends during the lockdown using the phone and social networks, while young children may have been more lonely during their free time, spending more time with their families or engaged in activities involving electronic devices. Consistent with previous research $\left[{ }^{28}\right]$, boys had higher scores than girls on all dimensions except for social support and peer interactions. Moreover, in line with previous findings [21, 29], the effects of age on gender differences in HRQoL were especially pronounced in this study. Our results with regard to the psychological dimension confirm previous findings that showed that girls have a relatively higher risk of self-perceived poor health in adolescence [21, 30-31].

In addition, moderate to good levels of agreement between the children's and parents' responses were found for all KIDSCREEN-27 dimensions. Levels of agreement or discrepancies between the parent and child perspectives with regard to HRQoL serve as 
additional information regarding the effects of the COVID-19 pandemic on the lives of children and their families. Our findings generally confirm the patterns of agreement observed in other European countries using KIDSCREEN-27 [28, 32]. They showed stronger agreement on domains that measure more observable aspects (e.g., physical well-being) and worse agreement on domains that measure less observable aspects, such as psychological well-being. These findings lend further support to results from the literature on HRQoL that have demonstrated that the agreement between child and parent ratings is stronger for physical health than for psychosocial health [33]. The HRQoL questionnaires were completed at home, so it is possible that parents sometimes helped their children answer the questions, which would increase the level of agreement [34]. The scores for all dimensions were underestimated by the parents. Lower parents' ratings could be influenced by their own concerns and worries regarding the lockdown and the pandemic or by their own health conditions. Visual inspection of the Bland-Altman plot also revealed that the agreement between child-parent dyads was stronger when the children had lower HRQoL scores, highlighting that parents have a good perception of children's well-being when it is impaired. In contrast with a previous study [35], our findings suggest that the sex of the child may affect the degree of agreement between child and parent ratings. The differences between child and parent ratings indicate that it would be valuable to consider both parent and child ratings. Further research is needed to determine which characteristics of the children and parents affect the level of agreement in their ratings with regard to HRQoL.

The study has some limitations and strengths. Among the strengths, this study is the first study to evaluate HRQoL in children and adolescents during the COVID-19 pandemic and the agreement between child and parent ratings. Research on HRQoL in children and adolescents is lacking in comparison to HRQoL research conducted in the adult population. Thus, given the timing of the collection of data, this study provides valuable information that will be useful for gaining insight into children's feelings during the first lockdown due to the COVID-19 pandemic; such information could be valuable during future lockdowns. As a limitation, the sample was composed of children recruited through an online survey. For this reason, it is difficult to generalize our results to either the entire French population of children and adolescents or to populations of children and adolescents in other countries. Children, adolescents and their parents in other countries might respond differently to being in lockdown and the need for social distancing. Larger surveys that involving collaborations among researchers from different countries should be conducted to increase the generalizability of the findings.

The self-reported scores on all domains of quality of life were lower among children and adolescents who experienced the first lockdown during the COVID-19 pandemic than among a large, representative, normative European sample. From the findings of this study, several key messages can be drawn. First, these findings highlight the need to develop programs to promote social communication among children, as very low levels of social support and peer interactions were reported by children and adolescents in a French area that has been particularly affected by COVID-19. Second, precautionary measures must be initiated among vulnerable groups, such as adolescents with mental health problems or chronic diseases, whose HRQoL is already poor. Future studies should also identify the factors that influence children's HRQoL to facilitate the development of effective interventions to support healthy development during the current crisis.

\section{Declarations}

Authors' contributions: SB-B, CB, MB and CT conceptualised the project and conducted the search with input from KL and HR. All authors were involved with data extraction and validation. HR conducted the data analysis with support from CB. SB-B and CB interpreted the data with support from HR. SB-B wrote the first draft of the manuscript. All authors were involved in editing and approving the manuscript. The corresponding author attests that all listed authors meet authorship criteria and that no other meeting the criteria have been omitted. SB-B and CB act as guarantors.

Acknowledgements: The study participants, without whom this publication could not have been possible.

Competing interests: The authors have no conflicts of interest to disclose.

Availability of data and materials: The data collected and analyzed during the current study can be availed by the corresponding author on request. 
Ethical approval and consent to participate: All procedures were conducted in accordance with the principles of the Declaration of Helsinki. The survey was anonymous to ensure the confidentiality and reliability of the data. The study protocol was approved by the Institutional Review Board (Comité National Informatique et Liberté-registration 2220408). All participants received detailed information regarding the purpose of the study and provided online informed consent to participate in the study.

Funding: No funding

\section{References}

[1] Zhu N, Zhang D, Wang W, et al. A novel coronavirus from patients with pneumonia in China, 2019. N Engl J Med. 2020; 382, 727-33

[2] Phelan AL, Katz R, Gostin LO. The novel coronavirus originating in Wuhan, China: callenges for global health governance. JAMA. 2020 doi:10.1001/jama.2020.1097

[3] World Health Organization. 2019-nCoV outbreak is an emergency of international concern.

http://www.euro.who.int/en/healthtopics/emergencies/pages/news/news/2020/01/2019

ncov-outbreak-is-an-emergency-of-international-concern.

[4] Bao Y, Sun Y, Meng S, Shi J, Lu L. 2019-nCoV epidemic: address mental health care to empower society. Lancet. 2020 Feb 22;395(10224):e37-e38. doi: 10.1016/S0140-6736(20)30309-3. Epub 2020 Feb 7.

[5] Marques de Miranda D, da Silva Athanasio B, Sena Oliveira AC, Simoes-E-Silva AC.

How is COVID-19 pandemic impacting mental health of children and adolescents? Int J Disaster Risk Reduct. 2020 Dec;51:101845. doi: 10.1016/j.ijdrr.2020.101845. Epub 2020 Sep 10.PMID: 32929399

[6] Singh S, Roy D, Sinha K, Parveen S, Sharma G, Joshi G. Impact of COVID-19 and lockdown on mental health of children and adolescents: A narrative review with recommendations. Psychiatry Res 2020 Nov;293:113429. doi:

10.1016/j.psychres.2020.113429. Epub 2020 Aug 24.PMID: 32882598

[7] Guessoum SB, Lachal J, Radjack R, Carretier E, Minassian S, Benoit L, Moro MR. Adolescent psychiatric disorders during the COVID-19 pandemic and lockdown.

Psychiatry Res. 2020 Sep;291:113264. doi: 10.1016/j.psychres.2020.113264. Epub 2020 Jun 29.PMID: 32622172

[8] Wang G, Zhang Y, Zhao J, Zhang J, Jiang F. Mitigate the effects of home confinement on children during the COVID-19 outbreak. Lancet. 2020 Mar 21;395(10228):945-947. doi: 10.1016/S0140-6736(20)30547-X. Epub 2020 Mar 4.

[9] Viner RM, Russell SJ, Croker H, Packer J, Ward J, Stansfield C, Mytton O, Bonell C, Booy R.School closure and management practices during coronavirus outbreaks including COVID-19: a rapid systematic review. Lancet Child Adolesc Health. 2020 May;4(5):397-404. doi: 10.1016/S2352-4642(20)30095-X. Epub 2020 Apr 6.

[10] Shah K, Mann S, Singh R, Bangar R, Kulkarni R. Impact of COVID-19 on the Mental Health of Children and Adolescents. Cureus. 2020 Aug 26;12(8):e10051. doi: 10.7759/cureus.10051.PMID: 32999774

[11] Sümen A, Adibelli D. The effect of coronavirus (COVID-19) outbreak on the mental well-being and mental health of individuals. Perspect Psychiatr Care. 2020 Oct 26. doi: 10.1111/ppc.12655. Online ahead of print.PMID: 33103787

[12] Marker AM, Steele RG, Noser AE. Physical activity and health-related quality of life in children and adolescents: A systematic review and meta-analysis. Health Psychol. 2018 Oct;37(10):893-903. doi: 10.1037/hea0000653.PMID: 30234348

[13] Zhou SJ, Zhang LG, Wang LL, Guo ZC, Wang JQ, Chen JC, Liu M, Chen X, Chen JX. 
Prevalence and socio-demographic correlates of psychological health problems in Chinese adolescents during the outbreak of COVID-19. Eur Child Adolesc Psychiatry. 2020 Jun;29(6):749-758. doi: 10.1007/s00787-020-01541-4. Epub 2020 May 3.

[14] Xie X, Xue Q, Zhou Y, Zhu K, Liu Q, Zhang J, Song R. Mental Health Status Among Children in Home Confinement During the Coronavirus Disease 2019 Outbreak in Hubei Province, China. JAMA Pediatr. 2020 Sep 1;174(9):898-900. doi:

10.1001/jamapediatrics.2020.1619.PMID: 32329784

[15] Zhang C, Ye M, Fu Y, Yang M, Luo F, Yuan J, Tao Q. The Psychological Impact of the COVID-19 Pandemic on Teenagers in China. J Adolesc Health. 2020 Dec; 67(6) : 747-755. PMID: 33041204

[16] Shen K, Yang Y, Wang T, Zhao D et al. Diagnosis, treatment, and prevention of 2019 novel coronavirus infection in children: experts' consensus statement. World J Pediatr. 2020 Jun;16(3):223-231. doi: 10.1007/s12519-020-00343-7. Epub 2020 Feb 7.PMID: 32034659

[17] Adıbelli D, Sümen A. The effect of the coronavirus (COVID-19) pandemic on health-related quality of life in children Child Youth Serv Rev. 2020 Dec;119:105595. doi: 10.1016/j.childyouth.2020.105595. Epub 2020 Oct 13.PMID: 33071408

[18] Chen F, Zheng D, Liu J, Gong Y, Guan Z, Lou D. Depression and anxiety among adolescents during COVID-19: A crosssectional study. Brain Behav Immun. 2020 Aug;88:36-38. doi: 10.1016/j.bbi.2020.05.061. Epub 2020 May 25.PMID: 32464156

[19] Vallejo-Slocker L, Fresneda J, Vallejo MA. Psychological Wellbeing of Vulnerable Children During the COVID-19 Pandemic. Psicothema. 2020 Nov;32(4):501-507. doi: 10.7334/psicothema2020.218.PMID: 33073755

[20] Ravens-Sieberer U, Herdman M, Devine J, Otto C, Bullinger M, Rose M, Klasen F.

The European KIDSCREEN approach to measure quality of life and well-being in children: development, current application, and future advances. Qual Life Res. 2014 Apr;23(3):791-803. doi: 10.1007/s11136-013-0428-3. Epub 2013 May 18.PMID: 23686556

[21] Ravens-Sieberer U, Auquier P, Erhart M, Gosch A, Rajmil L, the European KIDSCREEN Group, et al. The KIDSCREEN-27 quality of life measure for children and adolescents: psychome- tric results from a cross-cultural survey in 13 European countries. Qual Life Res. 2007;16:1347-56

[22] Robitail S, Ravens-Sieberer U, Simeoni MC, Rajmil L, Bruil J, the KIDSCREEN Group, et al. Testing the structural and crosscultural validity of the KIDSCREEN-27 quality of life questionnaire. Qual Life Res. 2007;16:1335-45

[23] KIDSCREEN Group. (2006). The KIDSCREEN questionnaires- Quality of life questionnaires for children and adolescentsHandbook. Lengerich: Papst Science Publisher

[24] Bartko JJ. The intraclass correlation coefficient as a measure of reliability. Psychol Rep. 1966;19(1):3-11. doi: 10.2466/pr0.1966.19.1.3

[25] Bland JM, Altman DG. Comparing methods of measurement: why plotting difference against standard method is misleading. Lancet. 1995 Oct 21;346(8982):1085-7. doi: 10.1016/s0140-6736(95)91748-9.PMID: 7564793

[26] Hirschfeld G, von Brachel R, Thiele C. Screening for health-related quality of life in children and adolescents: Optimal cut points for the KIDSCREEN-10 for epidemiological studies. Qual Life Res. 2020; 29(2):529-36.

[27] Riiser K, Helseth S, Haraldstad K, Torbjørnsen A, Richardsen KR. Adolescents' health literacy, health protective measures, and health-related quality of life during the Covid-19 pandemic. PLoS One. 2020 Aug 28;15(8):e0238161. doi:

10.1371/journal.pone.0238161. eCollection 2020.PMID: 32857806

[28] Berman AH, Liu B, Ullman S, Jadbäck I, Engström K. Children's Quality of Life Based on the KIDSCREEN-27: Child Self-Report, Parent Ratings and Child-Parent Agreement in a Swedish Random Population Sample PLoS One. 2016 Mar 9;11(3):e0150545. doi: 10.1371/journal.pone.0150545. eCollection 2016.PMID: 26959992

Page $11 / 13$ 
[29] Vingilis E. R., Wade T., \& Seeley J. S. (2002). Predictors of adolescent self-rated health. Analysis of the National Popula- tion Health Survey. Canadian Journal of Public Health, 93, 193-197

[30] Cavallo, F., Zambon, A., Borraccino, A., Ravens-Sieberer, U., Torsheim, T., Lemma, P., the Positive HBSC Health Group (2006). Girls growing through adolescence have a higher risk of poor health. Quality Life Research, 15, 1577-1585.

[31] Bisegger, C, Cloetta, B., von Rueden, U., Abet, T., Ravens- Sieberer, U., the European KIDSCREEN group (2005). Health- related quality of life: gender differences in childhood and adolescence. Social and Preventive Medicine, 50, 281-

[32] Stevanovic D, Tadic I, Novakovic T, Kisic-Tepavcevic D, Ravens-Sieberer U. Evaluating the Serbian version of the KIDSCREEN quality of life questionnaires : reliability, validity and agreement between children's and parents' ratings. Qual Life Res. 2013 Sep;22(7):1729-37. doi: 10.1007/s11136-012-0286-4. Epub 2012 Oct 7.PMID: 23054498

[33] Eiser C. \& Morse R. Quality-of-life measures in chronic diseases of childhood. Health Technology Assessment 2001; 5, 1-157

[34] Dey M, Landolt MA, Mohler-Kuo M. Assessing parent-child agreement in health-related quality of life among three health status groups. Soc Psychiatry Psychiatr Epidemiol. 2013 Mar;48(3):503-11. doi: 10.1007/s00127-012-0556-z. Epub 2012 Aug 5.PMID: 22864560

[35] Poulain T, Vogel M, Meigen C, Spielau U, Hiemisch A, Kiess W. Parent-child agreement in different domains of child behavior and health. PLoS One. 2020 Apr 9;15(4):e0231462. doi: 10.1371/journal.pone.0231462. eCollection 2020.PMID: 32271851

\section{Figures}
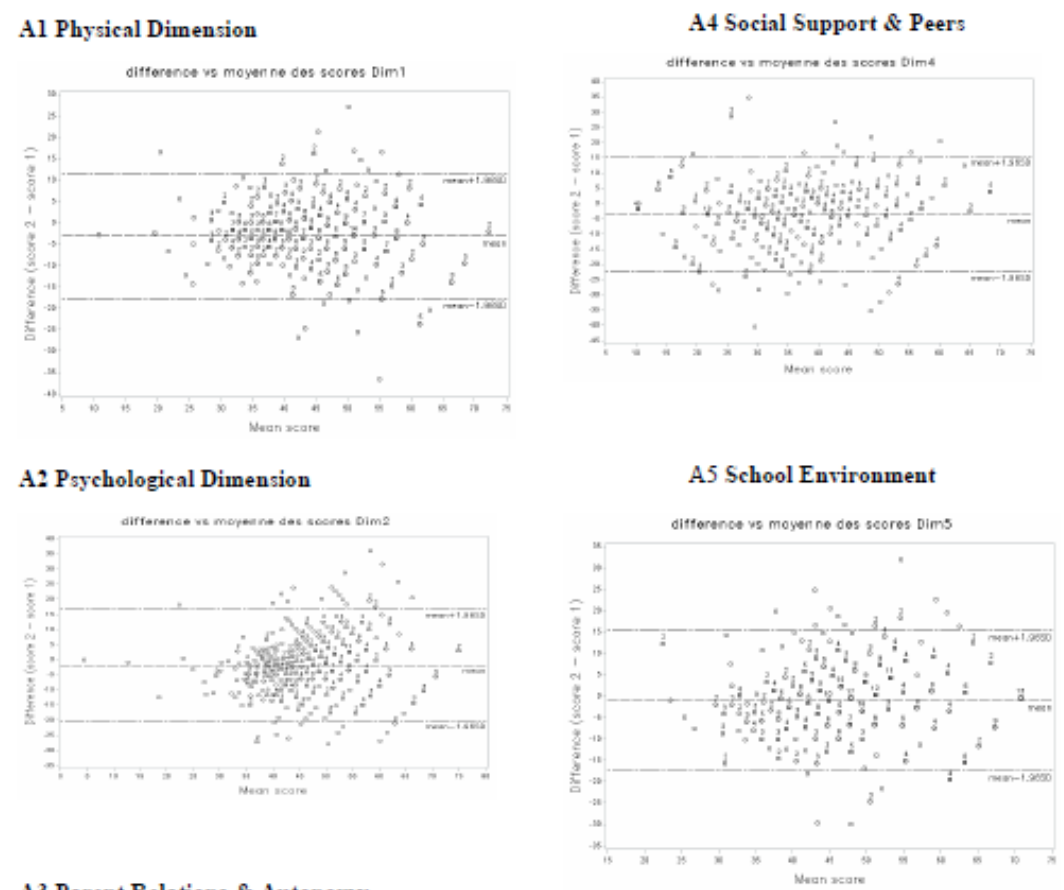

A3 Parent Relations \& Autonomy

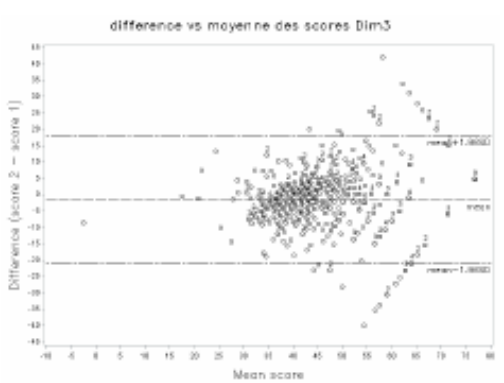




\section{Figure 1}

Scatter plots of pairwise agreements between parent and child scores on KIDSCREEN-27 ( $\mathrm{N}=471)$ Score 1 = KIDSCREEN-27 child, Score 2 =KIDSCREEN-27 parent 